\title{
Peertechz
}

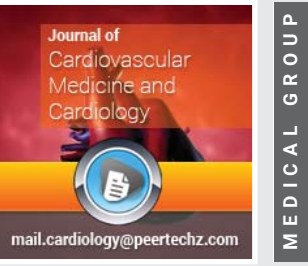

\section{Rare complication of lateral abdominal wall hematoma after coronary angioplasty}

\section{Ramesh Natarajan*}

Senior Consultant Cardiologist, Department of Cardiology, Kerala Institute of Medical Sciences,

Trivandrum, Kerala, India
Received: 19 August, 2020

Accepted: 28 August, 2020

Published: 29 August, 2020

*Corresponding author: Ramesh Natarajan, Senior Consultant Cardiologist, Department of Cardiology, Kerala Institute of Medical Sciences, Trivandrum,

Kerala, India, Tel: +919349329698

E-mail: natarajanramesh79@gmail.com

drramesh.natarajan@kimsglobal.com

ORCID: https://orcid.org/0000-0002-6238-149X

Keywords: Percutaneous coronary intervention; Abdominal hematoma; Femoral artery

https://www.peertechz.com

Check for updates

\section{Abstract \\ Abdominal wall hematoma is a rare but potentially serious complication that may develop after percutaneous coronary interventional procedures. In particular, an oblique muscle hematoma caused by injury to the superficial circumflex iliac branch of the femoral artery is very rare. Most of these cases can be managed by conservative measures including hydration and blood component transfusion. However, when active bleeding continues, angiographic embolization or surgery might be needed. Here, we report an uncommon case of lateral abdominal wall hematoma following left femoral artery puncture during the performance of percutaneous coronary intervention by the retrograde approach in a totally occluded right coronary artery.}

\section{Introduction}

Vascular complications are one of the most frequent adverse outcomes associated with percutaneous coronary intervention (PCI) through the femoral artery. They contribute to inhospital morbidity, mortality, and costs and are associated with increased long-term risk of myocardial infarction and death $[1,2]$. The common vascular complications include bleeding, pseudoaneurysm formation, groin hematoma, arteriovenous fistula, retroperitoneal bleeding, and other femoral arterial injuries requiring procedural or surgical intervention [3].

Abdominal wall hematoma is a rare complication that can present as acute abdomen following PCI $[4,5]$

In this report, we describe the case of a 60-year-old woman who developed lateral abdominal wall hematoma, following a PCI procedure through bifemoral approach for a totally occluded right coronary artery.

\section{Case report}

A 60-year-old lady presented to the outpatient department of our hospital with complaints of chest pain on effort for the past four months. She had no past history of diabetes or hypertension. Her physical examination was normal. She had normal renal functions; haemoglobin was $11.4 \mathrm{gm} \%$, blood sugar was normal with hba1c of 6.5 and lipid parameters were moderately deranged.

Electrocardiogram showed sinus rhythm with anterolateral ST segment depression and T wave inversions. Echocardiogram showed normal biventricular function and no wall motion abnormalities Figure 1.

Coronary angiogram done through the right radial route revealed critical triple vessel coronary artery disease with a Chronic Total Occlusion (CTO) of the right coronary artery and she was advised revascularisation. The patient opted for

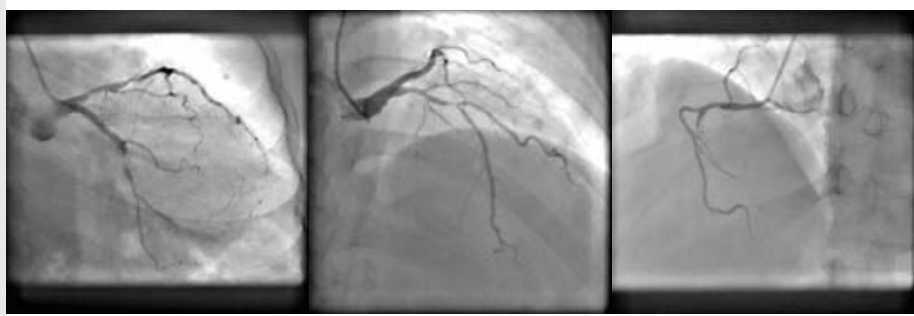

Figure 1: Coronary angiogram showing severe triple vessel disease. 
multivessel angioplasty in preference to Coronary bypass graft surgery (CABG) and she was scheduled for angioplasty of Left Anterior Descending (LAD) and Circumflex (CX) arteries, followed by staged angioplasty to Right Coronary Artery (RCA).

Angioplasty to LAD and CX was done without any complications during the same sitting as the angiogram, through the radial route and angioplasty to RCA was done after a week.

Patient was preloaded with clopidogrel 300mg and aspirin $300 \mathrm{mg} 6$ hours prior to the angioplasty of LAD and CX and the procedure was done under heparin cover to keep the Activated Clotting Time (ACT) around 300 seconds. The patient was discharged on clopidogrel 75mg daily, aspirin $150 \mathrm{mg}$ daily, atorvastatin $40 \mathrm{mg}$ once daily, metoprolol $25 \mathrm{mg}$ twice and ramipril $5 \mathrm{mg}$ once daily Figure 2.

The patient was readmitted 1 week later for RCA angioplasty. She was given an additional bolus of $300 \mathrm{mg}$ clopidogrel prior to the procedure.

Bilateral femoral artery punctures were done and 7French sheaths were placed for the СТО angioplasty procedure. Right Femoral Artery (RFA) puncture was done under fluoroscopic guidance, with the Seldinger needle pointing to the centre of the femoral head.

However during the left femoral artery puncture, resistance was felt during wire passage and fluoroscopy revealed that the wire had entered the superficial circumflex iliac branch of the femoral Artery .The wire could not be redirected to the iliac artery and hence both wire and needle were removed and manual compression given for achieving haemostasis after which a new puncture was done under fluoroscopic guidance.

\section{Femoral artery anatomy:}

The femoral artery gives off superficial and deep branches. There are four superficial branches of the femoral artery and these are:

- Superficial epigastric artery,

- Superficial circumflex iliac artery,

- External pudendal artery,

- Inguinal branches.

The femoral artery gives off three deep branches:

- Deep femoral artery or profunda femoris,

- Perforating arteries,

- Descending genicular artery.

Heparin 80oounits was administered (100 units per Kg body weight) to keep Activated Clotting Time (ACT) in the range of 300-350 seconds Figure 3.

RCA had a short segment CTO with bridging collaterals. Initial attempts to cross the CTO ante grade with dedicated CTO wires and micro catheter support were futile. Subsequently retrograde approach was used to cross the СТО successfully and a good result was obtained after placement of three long overlapping drug eluting stents Figure 4.

After the procedure the left femoral sheath was removed and vascular closure done with 6f Proglide vascular closure device (Abbott vascular, Santa Clara, California) [6,7]. Right femoral sheath was retained for 4hours, after which it was pulled out and haemostasis achieved by manual compression.

Four hours later, the patient developed vomiting associated with mild hypotension, with blood pressure of 90/70 $\mathrm{mm}$ hg. Blood pressure improved with IV fluids. She complained of pain over left side of abdomen which felt tense and tender to palpation. Left and right femoral puncture sites did not reveal any hematoma. However, blood investigations revealed significant drop in haemoglobin by nearly $3 \mathrm{gm} / \mathrm{dl}$.
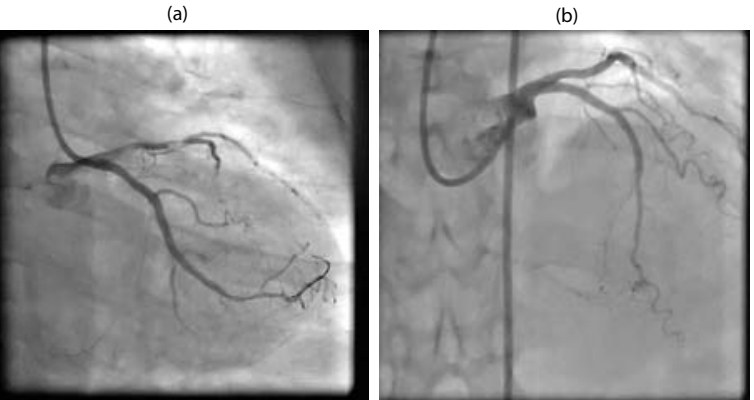

Figure 2: Left circumflex(a) and left anterior descending(b) arteries after angioplasty.

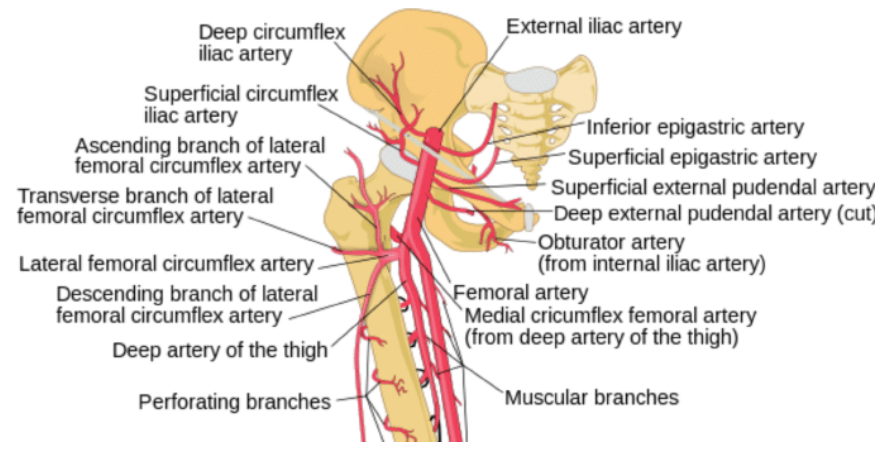

Figure 3: Branches of femoral artery- superficial circumflex iliac branch highlighted. (Adapted from Davies et al 12,13 BJR case reports). (a)

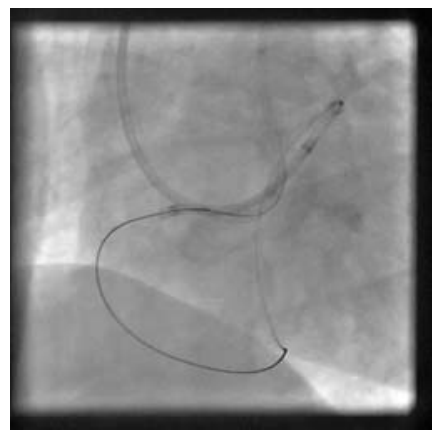

(b)

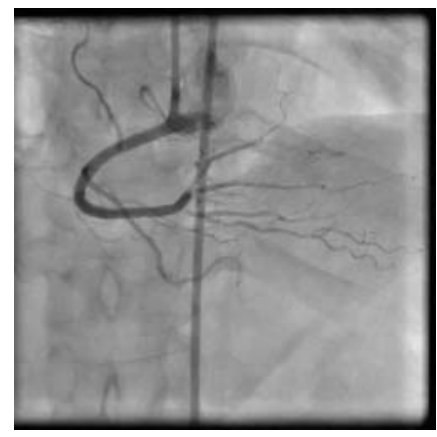

Figure 4: Right coronary angioplasty by retrograde approach through septa collaterals(a) and the final result after stenting(b). 
Retroperitoneal hematoma was suspected and an urgent bedside ultrasonographic examination was done which revealed a well-defined hypo echoic collection measuring 10x8 $2.5 \mathrm{~cm}$ over the left lateral abdominal wall in the intermuscular plane extending to left iliac fossa. No intra-abdominal collection was seen. The patient received two units of packed red cell transfusions along with analgesics for pain relief.

CT abdomen with contrast was done which revealed a hypo dense collection in left external oblique and internal oblique muscles, measuring $8.6 \times 1.5 \times 14$ centimetres. Significant subcutaneous oedema with free fluid and stranding was noted around the collection. No active contrast extravasation was seen from the left femoral artery or its branch the superficial circumflex iliac artery which was the likely culprit vessel responsible for the hematoma in this case. It was presumed that the accumulation of blood took place during the angioplasty procedure which was prolonged being a complex CTO intervention and because multiple doses of heparin were given during the procedure to keep ACT above 300 seconds.

Since there was no active extravasation in the CT angiogram and no hemodynamic instability, the patient was conservatively managed with blood transfusions, analgesics, bed rest and adequate hydration. Follow up ultrasonography after $\mathbf{2}$ days showed slight reduction in the size of the collection. In total she received 3 packed red cell transfusions after which her haemoglobin levels stabilised. She developed echymotic patches over the left flank and mild icterus secondary to the degradation of the accumulated haemoglobin, in the subsequent days, which improved gradually. She was discharged after 4 days in a stable condition.

\section{Discussion}

Abdominal wall hematoma is a rare but potentially serious vascular complication that may develop after cardiac and peripheral angiographic procedures. Predisposing factors include increased sheath size, repeat or multiple punctures of the artery, concomitant use of anticoagulants, advanced age, female sex, and hypertension [1-3].

Iatrogenic lateral abdominal wall hematomas often occur when the circumflex iliac branch of SFA is perforated during the insertion of the guide wires. These hematomas are distinguished from retroperitoneal hematomas, which occur when a physician unintentionally punctures the inferior epigastric artery or cannulates the femoral artery too superiorly.

The common symptoms of abdominal wall hematoma are the sudden onset of abdominal pain and swelling, which usually occurs several hours after the procedure. Because of its rarity, abdominal wall hematoma can be mistaken for several common acute abdominal conditions, such as appendicitis, sigmoid diverticulitis, perforated ulcers, ovarian cyst torsion, tumours, retroperitoneal hematoma and incarcerated inguinal hernias [5]. Diagnosis can be made clinically by the appearance of an obvious swelling or bruising, or may include non-specific findings, such as anaemia and fever.
Imaging studies help to confirm the diagnosis and exclude intra-abdominal or retroperitoneal haemorrhage. Contrastenhanced CT as well as digital subtraction angiography (DSA) can detect and evaluate active bleeding from a perforation site $[1,4,5]$. Conservative management, including bed rest and analgesics, is appropriate for most stable patients. However, when a patient has evidence of sustained bleeding or haemodynamic instability, angiographic interventions or surgery should be considered $[8,9]$.

In order to prevent vascular complications, puncturing the femoral artery under fluoroscopy guidance should be considered [10]. After the artery has been successfully punctured, the guide wire must be smoothly advanced through the needle. The cornerstone of safe sheath engagement is to stop when resistance is encountered during the insertion of the guide wire. Difficulty in advancing the guide wire may occur when the wire enters a small branch vessel as occurred in this case. After confirming the location of a wire by fluoroscopy, one can then retract the wire, spin it gently, and try advancing it again.

Because hydrophilic guide wires tend to unintentionally engage small vessels, replacing the straight hydrophilic guide wire with a J-tipped wire or using Teflon coated wires can be one strategy for preventing the perforation of smal vessels [10]. In general, it cannot be overemphasized that it is important to closely observe patients who have undergone PCI through femoral route, especially those with predisposing factors for bleeding [11-13].

In the present case, the patient had a rare complication of abdominal wall hematoma after a PCI procedure, in the absence of any immediate local vascular complications. We presume that the injury to the circumflex branch of the superficial femoral artery during guide wire insertion, the subsequent prolonged ACT associated with the use of peri procedural heparin and the lengthy complex procedure, all were responsible for this complication.

When vascular complications are suspected during the procedure, deferral of the PCI procedure and prompt management of the vascular complication should be considered to ensure a patient safety.

\section{References}

1. Fukunaga N, Ikeyama S, Satomi J, Satoh K (2009) Lateral abdominal wall hematoma as a rare complication after carotid artery stenting: a case report. World J Emerg Surg 4: 39. Link: https://bit.ly/2G9rKRC

2. Merriweather N, Sulzbach-Hoke LM (2012) Managing risk of complications at femoral vascular access sites in percutaneous coronary intervention. Crit Care Nurse 32: 16-29. Link: https://bit.ly/3jm2p5h

3. Shimizu T, Hanasawa K, Yoshioka T, Mori T, Kajinami T, et al. (2003) Spontaneous hematoma of the lateral abdominal wall caused by a rupture of a deep circumflex iliac artery: report of two cases. Surg Today 33:475-478. Link: https://bit.ly/3b5IQeu

4. Ranieri P, Bianchetti A, Robecchi D, Trabucchi M (2009) Spontaneous hematoma of the lateral abdominal wall: a case report. J Am Geriatr Soc 57 2375-2376. Link: https://bit.ly/3gGefp9

5. Shimodaira M, Kitano T, Kibata M, Shirahata K (2013) An oblique muscle 
hematoma as a rare cause of severe abdominal pain: a case report. BMC Res Notes 6: 18. Link: https://bit.ly/2D8Irvg

6. Hamel WJ (2009) Femoral artery closure after cardiac catheterization. Crit Care Nurse 29: 39-46. Link: https://bit.ly/2YGgNgl

7. Bangalore S, Bhatt DL (2011) Femoral arterial access and closure. Circulation 124: e147-156. Link: https://bit.ly/3lse8RF

8. Jabr FI, Skeik N (2011) Spontaneous lateral abdominal wall hematoma complicating chronic obstructive pulmonary disease exacerbation. J Med Liban 59: 1600-1601. Link: https://bit.ly/3hEss7p

9. Luhmann A, Williams EV (2006) Rectus sheath hematoma: a series of unfortunate events. World J Surg 30: 2050-2055. Link: https://bit.ly/3lpA28d
10. Fitts J, Ver Lee P, Hofmaster P, Malenka D (2008) Northern New England Cardiovascular Study Group. Fluoroscopy-guided femoral artery puncture reduces the risk of $\mathrm{PCl}-$ related vascular complications. J Interv Cardiol 21: 273-278.

11. Dutta S, Sanjay P, Jones ML (2009) Diagnosis and treatment of giant lateral abdominal wall haematoma after blunt trauma: a case report. Cases J 2: 9358. Link: https://bit.ly/3gEBCPR

12. Ruiz Villareal M (2015) Thigh arteries schema. Link: https://bit.ly/3b8Hqjt

13. Davies J, Metcalfe J, Ward R (2016) Posterior common femoral branch pseudoaneurysm: an unusual arterial complication following femoral venous access. BJR Case Rep 2: 20150335. Link: https://bit.ly/2D84dPJ

\section{Discover a bigger Impact and Visibility of your article publication with}

\section{Peertechz Publications}

\section{Highlights}

* Signatory publisher of ORCID

* Signatory Publisher of DORA (San Francisco Declaration on Research Assessment)

* Articles archived in worlds' renowned service providers such as Portico, CNKI, AGRIS, TDNet, Base (Bielefeld University Library), CrossRef, Scilit, J-Gate etc.

* Journals indexed in ICMJE, SHERPA/ROMEO, Google Scholar etc.

* OAI-PMH (Open Archives Initiative Protocol for Metadata Harvesting)

* Dedicated Editorial Board for every journal

* Accurate and rapid peer-review process

* Increased citations of published articles through promotions

* Reduced timeline for article publication

Submit your articles and experience a new surge in publication services (https://www.peertechz.com/submission).

Peertechz journals wishes everlasting success in your every endeavours.

Copyright: ( 2020 Natarajan R. This is an open-access article distributed under the terms of the Creative Commons Attribution License, which permits unrestricted use, distribution, and reproduction in any medium, provided the original author and source are credited. 